\title{
Assessment of Factors Those Induce Females to Engage into Prostitution In case of Hossana Town, South Ethiopia
}

\author{
Getachew Tekle* and Wondimu Fikre \\ Department of Statistics, College of Natural and Computational Sciences, Wachemo University, Ethiopia
}

*Corresponding author: Getachew Tekle, Department of Statistics, College of Natural and Computational Sciences, Hossana, Ethiopia

\section{ARTICLE INFO}

Received: 慧 November 26, 2019

Published: December 05, 2019

Citation: Getachew Tekle, Wondimu Fikre. Assessment of Factors Those Induce Females to Engage into Prostitution In case of Hossana Town, South Ethiopia. Biomed J Sci \& Tech Res 23(4)-2019. BJSTR. MS.ID.003930.

Keywords: Prostitution; Determining Factors; Logistic Regression

\begin{abstract}
Prostitution is the business or practice of engaging in sexual relation in exchange for payment or some other benefit. It is illegal in some countries and is divided into four types. The main purpose of this study was to identify factors that induce females to engage into prostitution at Hossana town. Logistic regression models were applied to describe and to analyze the data. The totals of 70 selected females from Hossana town were eligible for this study. Among these females 34(48.6\%) are interested in and like prostitution while $36(51.4 \%)$ are prostitutes but do not like or not interested in prostitution. The proportion of prostitution practice is larger $41(58.6 \%, \mathrm{P}=0.0149)$ for adolescent age groups than the youth females. Females from the religion of protestant $(40.0 \%, \mathrm{P}=0.00536)$ are more likely to be prostitutes as compared to Muslim. The proportion of prostitution practice is large for smokers as compared to non-smokers $38(54.3 \%, \mathrm{P}=0.0344)$. The consequence of prostitution is revealed to bear child $32(45.7, \mathrm{P}=0.0101)$. As the result reveals, the determining factors for females engaged into prostitution are age level (adolescent), religion type (protestant), family life status(alive), habit of smoking(smokers), addiction (chewing khat), childbearing. Though it is impossible to demolish the Prostitution absolutely, the act should not be tolerated, and the attitudes of females should be changed, refreshed and they should be clean minded.
\end{abstract}

\section{Introduction}

\section{Background of the Study}

Prostitution is the business or practice of engaging in sexual relation in exchange for payment or some other benefit. It is illegal in some countries and is divided by four branches. There is street prostitution, house-based prostitution, phone-based prostitution and hotel-based prostitution (Free Merriam-Webster Dictionary [1], 2013; Prostitution Law \& Legal Definition, 2013) [2]. Street prostitution is a form of sex work in which women engage in sexual activity working on streets. These women commonly work during night-time sat majority of road sites, main streets, in front of bars and other hot spot areas in which their clients visit commonly for entertainment and drinking purpose.

A. House Based Prostitution: - This kind of prostitution is performed at their own houses and some house owners which sells alcoholic drinks.
B. Phone Based Prostitution: - This kind of prostitution is performed at a hotel, girls leave their phone numbers and photos at a hotel room and where ever they got a call they perform their duty.

C. Hotel Based Prostitution: - This kind of prostitution is performed at a hotel; this type of works got a room at that hotel and spends their day time in there then start working at night time.

Women have been tricked into prostitution with guarantees of decent job opportunity in the town or abroad or have been kidnapped and the forced to work as prostitution. Family expectation and problem are common factors why many enter the prostitution business. Women in a particular area pressured to pay their Sibling educations or support a sick family number. Other aspect such as a functional family or constraints the abuse from parents have led ad- 
olescent to leave their homes and are attracted by the easy profile's profits from prostitution. Women who appear entirely powerless and incapable of setting the boundary of the sexual activity to take place will attract men who may wish to legitimate on act of sexual abuse by Payment of cash Prostitution [3]. Poverty and unemployment have triggered the rapid spread of prostitution in the town. It provides those involved in this profession a considerable amount of income to support their families as well as a supply steady flow of remittance from urban to rural areas or from prostitutes working overseas. Prostitutes exist for most because there is a demand, without clients there is no prostitution.

Moreover, the demand is present because men think that it is legitimate to pay women to satisfy their sexual needs. The most inebriated prostitutes on street appear to be the most successful at attracting clients. Women who appear entirely powerless and incapable of setting the boundaries of the sexual activity to take place will attract men who may wish to legitimate an act of sexual abuse by payment of cash. Indeed, there is relation between low economic statuses with their involvement in prostitution. Unemployment, poor education, few available jobs, peer pressure, orphanage, sex desire, easy employment concept, inadequate salaries are some factors women to enter in prostitution [4].

\section{Statement of the Problem and Research Questions}

In both urban and rural, some parents have no harmonious relationship with their children. This enforces children to leave their homes or place of birth and migrate from rural areas to urban area. Especially, females are the most risky to problems like that of prostitution. Most of the rural females are migrants to urban area for searching jobs, better life etc. After their migration they face no jobs and without income there is no better life in urban area so that they engage in prostitution life to help their family like brothers and sisters. On the other hand, some female university students having fewer grades lead them to engaging on prostitution [5].

There is unexpected discrepancy between modern contraceptive services and high levels of unwanted pregnancy and unsafe abortion on the other hand as the consequence of this act. According to the study by World Health Organization (WHO) the reason for this is societal change caused by rapid industrialization and urbanization lead to loosening of family ties and erosion of traditional sanctions that inhibited premarital sexual activity. Younger age of menarche, combined with delayed age of marriage, and adolescents are increasingly forced to learn \& exercise sexual activities from their peers and mass media [6]. Here the gap that was supposed to be filled by this study is indicating factors inducing females to engage in prostitution in this selected study area.

Hence, the current study is supposed to answer the following basic research questions:

a) What are the factors inducing females in Hossana town to involve in prostitution? b) What is the prevalence of sexual business in town?

c) What are the consequences of prostitution?

\section{Objectives}

General Objective: The General objective of this study was to identify factors that induce females to engage into prostitution at Hossana town, South Ethiopia.

\section{Specific Objectives:}

a) To find out determining factors that induce females to engage into prostitution

b) To determine the association and prevalence of prostitution in the town

c) To determine the consequences of prostitution in the town

\section{Significance of the Study}

a) This study helps to know whether those variables that induces females in prostitution in Hossana town and to find the best way to distinguish the effect of the variable

b) It is important to create awareness for the prostitutes how to manage their life

c) It will be a good lesson for those not involved in sexual business

\section{Method of Data Analysis}

\section{Description of Study Areas and Period}

Hadiya zone is one of 13 zones in SNNPR. There are 10 woredas and one town administration in Hadiya zone. Hosanna town is administrative center for Hadiya zone and it is $235 \mathrm{~km}$ away from Addis Ababa.

\section{Sample size, Sampling Design and Technique}

For this study cross-sectional study design was employed. In order to select a fairly representative sample of the population for this study, simple random sampling technique was employed. Given the illegality and intimate nature of prostitution, the researcher selected seventy prostitutes/sex workers from the town who were used for this study (due to its nature, it's difficult to determine the exact number of prostitutes, but implied subjects were taken). In this technique, the researcher begun with an initial interview or key informant who was then be asked to refer to her acquaintances. This technique was deemed to be the best under the current circumstances in which the activity is criminalized, hence was done clandestinely.

\section{Variables Considered in the Study}

Dependent Variable: The dependent variable is females' prostitution status which is a binary outcome (coded as $0=$ when 
a female did not engaged into prostitution and $1=$ when a female engaged into prostitution).

\section{Independent Variables: (Table 1)}

\section{Data Analysis}

The method of data analysis is used for any study depends on the nature of the variables incorporated in the study, the data type of the major variable in the studied population, the aim in the study come up at the end of the study. Some descriptive measures like mean, median, standard deviation, frequencies and percentages of number of prostates were calculated using the commonly used statistical software like R.

Having identified and defined the variables, now the data was analyzed using some classical model by Binary logistic regression model as the outcome variable or dependent variable here is treated as binary, having two possible outcomes(coded as $0=$ when a female did not engage into prostitution and $1=$ when a female engaged into prostitution).

Logistic Regression Model: In statistics, logistic regression is a type of regression analysis used for predicting the outcome of a categorical dependent variable (a dependent variable that can take on a limited number of categories) based on one or more predictor variables. The probabilities describing the possible outcome of a single trial are modeled, as a function of explanatory variables, using a logistic function [7]. Cross tabulation was done before analyzing the data using logistic regression to check the association.

Logistic regression measures the relationship between a categorical dependent variable and usually a continuous independent variable (or several), by converting the dependent variable to probability scores. As such it treats the same set of problems as doe's probity regression using similar techniques. Also, logistic regression is used when the regressed, the dependent variable or the response variable is qualitative in nature or categorical, Qualitative response either binary (dichotomous) or multiple category [8]. Binomial or binary logistic regression is the form of regression, which is used when the dependent variable is dichotomous and the independent variables are of any type [9]. Logistic regression models are special cases of generalized linear models (GLMS) for binary data. The regression model when the dependent variable is qualitative our aim or objective is to estimate the expected or mean value given that the value of regresses, $E\left(Y_{i} / X_{1 i}-\cdots-X_{K i}\right)$.However, in logistic regression objective is to find the probability of something happening (probability of success, when a prostate has positive idea towards the act). Logistic regression is used in various areas of social sciences and medical research.

\section{Model Description}

The dependent variable in logistic regression is usually dichotomous, that is, the dependent variable can take the value " 1 " with probability of success (a female engaged into prostitution) or the value 0 with probability of failure (a female did not engage into prostitution). The model for logistic regression analysis assumes that the outcome variable $\mathrm{Y}$ is categorical, for example, binary or dichotomous. This model allows one to predict out comes, from set of variables may be continuous, discrete, and dichotomous or mix of any of these. The terminology binary logistic regression analysis the odd of success defined as to be the ratio of the probability of success to the probability of failure.

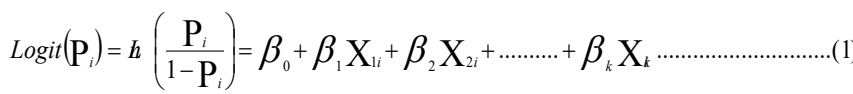

Where, are the model parameters and for this study the dependant and explanatory variables are defined as $\mathrm{Yi}=\{1$, when a female engaged into prostitution, if not 0$\}$ And also other explanatory variables may be included in this study based on the data collected from the respondent. Making some arrangements of equation (1) the above model or relation can be written as:

$$
P_{i}=P\left(Y_{i}=1 / x_{1}, x_{2} \ldots x_{k}\right)=\frac{e^{\eta_{i}}}{1+e^{\eta_{i}}} \text { (logistic regression function) }
$$

Where, $\eta_{i}=B 1+\sum_{i=0}^{K} B_{i} X_{i}$ and $\mathrm{X}_{0}=1$; Odd ratio, the probability of an event happing is

$$
\left(\frac{P_{i}}{1-P_{i}}\right) \text { for the } i^{\text {th }} \text { event as a success. That is }=\operatorname{Odd}\left(Y_{i}=1\right)=\left(\frac{P_{i}}{1-P_{i}}\right)
$$
$=e^{\eta_{i}}, \mathrm{i}=1,2 \ldots . \mathrm{k}$

After finding the odd ratio the interpretation will be applied for each explanatory variables with respect to the obtained odd ratio that is ebi.

\section{Parameter Estimation for Logistic Regression}

The maximum likelihood and non-iterative weighted least squares are the two most computing estimation methods used in fitting logistic regression model $[10,11]$ When the assumption of normality of the predictors does not hold, the non- iterative weighted least squares method is less efficient. In contrast, the maximum likelihood estimation method is appropriate for estimating the logistic model parameters due to this less restrictive nature of the underlying assumptions Hosmer Lemeshow (1989). Hence, in this study the maximum likelihood estimation technique will be applied to estimate parameters of the model. Consider the logistic model $\mathrm{P}(\mathrm{Yi}=1 \mid \mathrm{X})=\pi_{i}=\frac{e^{x \beta}}{1+e^{x \beta^{\prime \prime}}}$ Since observed values of $\mathrm{Y}$ say, $Y_{i}, s(i=1,2,3 \ldots ., n)$ are independently distributed as binomial with parameter the maximum likelihood function of $Y$ is given by:

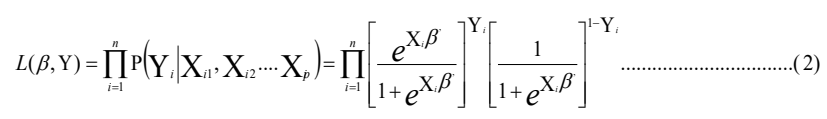

Where, $\beta>=\left(\beta_{1}, \beta_{2}, \beta_{3} \ldots \beta_{\mathrm{p}}\right)$

The objective of stating likelihood function is to get an estimator $\hat{\beta}=(\hat{\beta} 0, \hat{\beta} 1 \ldots . . \hat{\beta} p)$ of $\beta$ which maximizes the likelihood function 
expressed in equation (2). Since the likelihood equations are nonlinear in the parameters, the Newton-Raphson iterative maximum likelihood estimation method that expresses

$\hat{\beta}$ at the $(\mathrm{u}+1)^{\text {th }}$ at the $(\mathrm{u}+1)^{\text {th }}$ cycle of the iteration is expressed as $\hat{\beta}_{u+1}=\hat{\beta}_{u}\left(\mathrm{x} \hat{V}_{u} \mathrm{x}\right)^{-1} \mathrm{x}_{R_{u}}$, Where $\mathrm{u}=0,1,2,3, \ldots$ and $\hat{V}$ is a diagonal matrix $\hat{V}=\operatorname{diag}\left[\hat{\pi}_{i}\left(1-\hat{\pi}_{i}\right]=\operatorname{cov}(\mathrm{Y})\right.$, With its diagonal elements $\left.\mathrm{X}_{\mathrm{i}}=1\right)$. Finally, is the resultant maximum likelihood estimator of $\beta$ with residual [12]. $\Re=\mathrm{Y}-\hat{\pi}$ Newton's method usually converges to the maximum of the $\log$ - likelihood in just a few iteration unless the data are especially badly conditioned. All the parameters and estimates of $\mathrm{P}\left(\mathrm{Y}_{\mathrm{i}}=1 \mid \mathrm{X}\right)$ for each subject were computed using the R software.

\section{Ethical Consideration}

Ethical clearance was obtained from Wachemo University, research and community services coordinating office. And, the official ethical clearance and permition was also obtained from Hadiya zone and Kambata zone police affairs station offices. Careful due consideration was given for security of subjects and confidentiality was kept.

Table 1: Covariates and codes.

\section{Results and Discussion}

\section{Results}

Table 1 presents basic descriptive summary information that summarizes the associations between the determinant factors and prostitution status of females. The totals of 70 selected females from Hossana town were eligible for this study. Among these females $34(48.6 \%)$ are interested in and like prostitution while $36(51.4 \%)$ are prostitutes but do not like or not interested in prostitution. The proportion of prostitution practice is larger $41(58.6 \%)$ for adolescent age groups than the youth females $11(15.7 \%)$. The prostitution practice is larger $18(25.7 \%)$ for older age compared to youth females. There is also a remarkable variation of prostitution practices due to place of residence of females/prostitutes. The proportion of being a prostitute for urban females is $(27.1 \%)$ and who living in rural area is (72.9\%). The proportion of females being prostitutes varies based on their marital status. The proportion of being prostitute for single female (41.4\%) is larger than the married one $(27.1 \%)$. Females from the religion of protestant $(40.0 \%)$ are more likely to be prostitutes as compared to Muslim (25.7\%).

\begin{tabular}{|ll|l|}
\hline \multicolumn{1}{|c|}{ Covariates } & Codes \\
\hline 1. & Age at first sex & $0<=15 \mathrm{yrs}, 1=16-25 \mathrm{yrs}, 2=>26 \mathrm{yrs}$ \\
2. & Employment status & $0=$ unemployed, $1=$ employed \\
3. & Adequacy of salaries & $0=$ yes, $1=$ no \\
4. & Orphanage & $0=$ no, $1=$ yes \\
5. & Sex desire & $0=$ no, $1=$ yes \\
6. & Sex before prostitution & $0=$ no, $1=$ yes \\
7. & First sex & $0=$ by her desire, $1=$ by force \\
8. & Place of prostitute & $0=$ rural, $1=$ Urban \\
9. & Marital status & $0=$ married, $1=$ single, $2=$ separated $/$ divorced $/$ widow \\
10. & Level of education & $0=$ secondary and above, $1=$ no education, $2=$ primary \\
11. & Religion & $0=$ Muslim, $1=$ orthodox, $2=$ protestant, $3=$ others \\
12. Smoking & $0=$ no, $1=$ yes \\
13. & Bear child & $0=$ no, $1=$ yes \\
14. & Abortion & $0=$ no, $1=$ yes \\
15. & Reason for engagement & $0=$ by her desire, $1=$ by peer pressure, $2=$ to get employment easily \\
16. & Test result of sexually t. disease & $0=$ negative, $1=$ positive \\
& & \\
\hline
\end{tabular}

Most of the prostitutes started their first sex in their adolescent age level 16-25 years (50.0\%). Most of the females 38(54.3\%) stared the act when their families are alive. Females who leant primary education $44(62.9 \%)$ are most likely to be prostitutes as compared to those females at any level of education. Females who are unemployed $23(32.9 \%)$ are more likely to be prostitutes as compared to employed $18(25.7 \%)$. Most of the prostitutes get their clients from farmers $24(34.3 \%)$ next to other government workers like teachers and office workers $27(38.6 \%)$. The proportion of prostitution practice is large for smokers $38(54.3 \%)$ as compared to non-smokers 32(45.7). The act of prostitution varies with also addiction practice. The proportion of prostitution practice is large for alcoholic drinkers $19(27.1 \%)$ next to those free of addiction $30(42.9 \%)$. Most of them like sex ever before $45(64.3 \%)$. The proportion of females being prostitutes varies based on means of making their first sex. The proportion of prostitution practice is large for promise of gifts $32(45.7 \%)$ as compared to own desire $9(12.9 \%)$. The need of type of aid varies among the prostitutes. Most of them need the act to be legalized 32(45.7\%). 
The prevalence of prostitution is large for the way they get their clients on the street (road sites, main streets, in front of bars) $30(42.9 \%)$ as compared to them get their clients by living at hotel and get at night time $3(4.3 \%)$. Most of the females engaged into the prostitution life to support their sick/poor family $38(54.3 \%)$.
Prostitutes frequently face difficulties. Among them 35(50\%) of faced disagreement of number of turns; $24(34.3 \%)$ faced unwillingness of the clients to pay 11(15.7\%) faced pain, pregnancy, HIV, abortion, lacking interest, etc. (Table 2).

Table 2: Descriptive Summary of eliciting association among determinant factors and prostitution status of females.

\begin{tabular}{|c|c|c|}
\hline Variables & Categories & n (\%) \\
\hline \multirow{3}{*}{ Age of prostitutes } & less than/equal to 15 years & 11(15.7) \\
\hline & $16-25$ years & $41(58.6)$ \\
\hline & above 26 years & $18(25.7)$ \\
\hline \multirow{2}{*}{ Place of residence } & Urban & $19(27.1)$ \\
\hline & Rural & $51(72.9)$ \\
\hline \multirow{3}{*}{ Marital status } & married & $19(27.1)$ \\
\hline & single & $29(41.4)$ \\
\hline & separated/divorced/widowed & $22(31.4)$ \\
\hline \multirow{4}{*}{ Religion } & Muslim & $18(25.7)$ \\
\hline & Orthodox & $21(30.0)$ \\
\hline & Protestant & $28(40.0)$ \\
\hline & Other & $3(4.3)$ \\
\hline \multirow{3}{*}{ Age of first sex } & less than/equal to 15 years & $34(48.6)$ \\
\hline & $16-25$ years & $35(50.0)$ \\
\hline & above 26 years & $1(1.4)$ \\
\hline \multirow{2}{*}{ Do you like/are in prostitution } & No & $36(51.4)$ \\
\hline & Yes & $34(48.6)$ \\
\hline \multirow{2}{*}{ Family alive when you start prostitution } & No & $32(45.7)$ \\
\hline & Yes & $38(54.3)$ \\
\hline \multirow{4}{*}{ Level of education } & primary & $44(62.9)$ \\
\hline & secondary & $8(11.4)$ \\
\hline & tertiary & $6(8.6)$ \\
\hline & no education & $12(17.1)$ \\
\hline \multirow{4}{*}{ Employment status before Prostitution } & employed & $18(25.7)$ \\
\hline & unemployed & $23(32.9)$ \\
\hline & student & $11(15.7)$ \\
\hline & other & $18(25.7)$ \\
\hline \multirow{5}{*}{ Occupation of Clients } & farmers & $24(34.3)$ \\
\hline & commercials & $5(7.1)$ \\
\hline & teachers & $6(8.6)$ \\
\hline & other gov't workers & $27(38.6)$ \\
\hline & others & $8(11.4)$ \\
\hline \multirow{2}{*}{ Habit of Smoking } & no & $32(45.7)$ \\
\hline & Yes & $38(54.3)$ \\
\hline \multirow{4}{*}{ To what you are addicted? } & free of addiction & $30(42.9)$ \\
\hline & alcoholic drinks & $19(27.1)$ \\
\hline & chat & $13(18.6)$ \\
\hline & other related drugs & $8(11.4)$ \\
\hline \multirow{2}{*}{ Like sex ever before? } & No & $25(35.7)$ \\
\hline & Yes & $45(64.3)$ \\
\hline
\end{tabular}




\begin{tabular}{|c|c|c|}
\hline \multirow{4}{*}{ How did you make first sex? } & own desire & $9(12.9)$ \\
\hline & by force & $9(12.9)$ \\
\hline & Promise of gifts & $32(45.7)$ \\
\hline & others & $20(28.6)$ \\
\hline \multirow{4}{*}{ Type of aid you need if positive } & Act to be legalized & $32(45.7)$ \\
\hline & More Payment for the act & $4(5.7)$ \\
\hline & Every one to stand On the side of them & $14(20.0)$ \\
\hline & others & $20(28.6)$ \\
\hline \multirow{4}{*}{ How do you get your clients? } & $\begin{array}{l}\text { On the street (road sites, main streets, in } \\
\text { front of bars) }\end{array}$ & $30(42.9)$ \\
\hline & At house (selling alcoholic drinks) & $24(34.3)$ \\
\hline & $\begin{array}{l}\text { By leaving my phone number and photo } \\
\text { at hotels }\end{array}$ & $13(18.60$ \\
\hline & By living at hotel and get at night time & $3(4.3)$ \\
\hline \multirow{5}{*}{ Why did you enter this life? } & $\begin{array}{l}\text { Family Expectation (Poor and Unem- } \\
\text { ployed) }\end{array}$ & $13(18.6)$ \\
\hline & To support a sick/poor family & $38(54.3)$ \\
\hline & Peer pressure & $10(14.3)$ \\
\hline & Own interest (I like it, to get more money) & $8(11.4)$ \\
\hline & Other & $1(1.4)$ \\
\hline \multirow{4}{*}{ Why your colleagues enter this life? } & Unemployment/ poor education & $43(61.4)$ \\
\hline & $\begin{array}{l}\text { Few available jobs, easy Employment } \\
\text { concept, or Inadequate salaries }\end{array}$ & $19(27.1)$ \\
\hline & Peer Pressure, Orphanage, or Sex Desire & $7(10.0)$ \\
\hline & Other & $1(1.4)$ \\
\hline \multirow{3}{*}{ What difficulties prostitutes Face? } & Unwillingness of The Clients to Pay & $24(34.3)$ \\
\hline & Disagreement of Number of Turns & $35(50)$ \\
\hline & $\begin{array}{l}\text { Pain, Pregnancy, HIV, Abortion, Lacking } \\
\text { Interest, etc }\end{array}$ & $11(15.7)$ \\
\hline \multirow{2}{*}{ Prostitutes bear child? } & Yes & $51(72.9)$ \\
\hline & No & $19(27.1)$ \\
\hline \multirow{2}{*}{ Have you abort ever? } & Yes & $38(54.3)$ \\
\hline & No & $32(45.7)$ \\
\hline \multirow{3}{*}{ Test result of sexually disease } & Negative & $21(30.0)$ \\
\hline & Positive & $29(41.4)$ \\
\hline & Not Tested Yet & $20(28.6)$ \\
\hline \multirow{2}{*}{ If positive, do you need support? } & No & $19(27.1)$ \\
\hline & Yes & $51(72.9)$ \\
\hline \multirow{4}{*}{ How do you express this life? } & Happy Life & $14(20.0)$ \\
\hline & Full of Money & $15(21.4)$ \\
\hline & Miserable & $30(42.9)$ \\
\hline & Want to Quit & $11(15.7)$ \\
\hline \multirow{2}{*}{ Know average income since u started? } & Yes & $34(48.6)$ \\
\hline & No & $36(51.4)$ \\
\hline \multirow{2}{*}{ Income enough? } & Yes & $16(22.9)$ \\
\hline & No & $54(77.1)$ \\
\hline
\end{tabular}

The consequence of prostitution is revealed to bear child. Most of females engaged into the act of bearing child 51(72.9\%). As the consequence of prostitution abortion is common among most of the females engaged into the act. More than half of them abort during their act 38(54.3\%). Prostitutes are also exposed to sexually transmitted diseases. Among them in the study 29(41.4\%) are 
positive of sexually transmitted diseases like HIV. More than half of the responds in the study who are positive of STDs need support 51(72.9\%). Prostitution life expressed among the prostitutes differently. Although they are engaged into 30(42.9\%) of them expressed the life as miserable. Among those females 36(51.4\%) of them do not know their average income since they started the act and $54(77.1 \%)$ said the income they get from the act is not enough for their life.

Table 3: R-output for Binary Logistic Regression.

\section{Parameter Interpretation of Marginal Models}

Table 3 presents parameter estimates and their corresponding empirically corrected standard errors alongside the p-values from Binary Logistic regression model. Each parameter $\beta_{j}$ reflects the effect of factor $X_{1}$ on the log odds of the probability of being prostitute, statistically controlling all the other covariates in the model. Then, the odds ratio of variables is calculated as the exponent of $\beta_{\mathrm{j}}$ i.e. odds ratio $=\exp \left(\beta_{\mathrm{j}}\right)$.

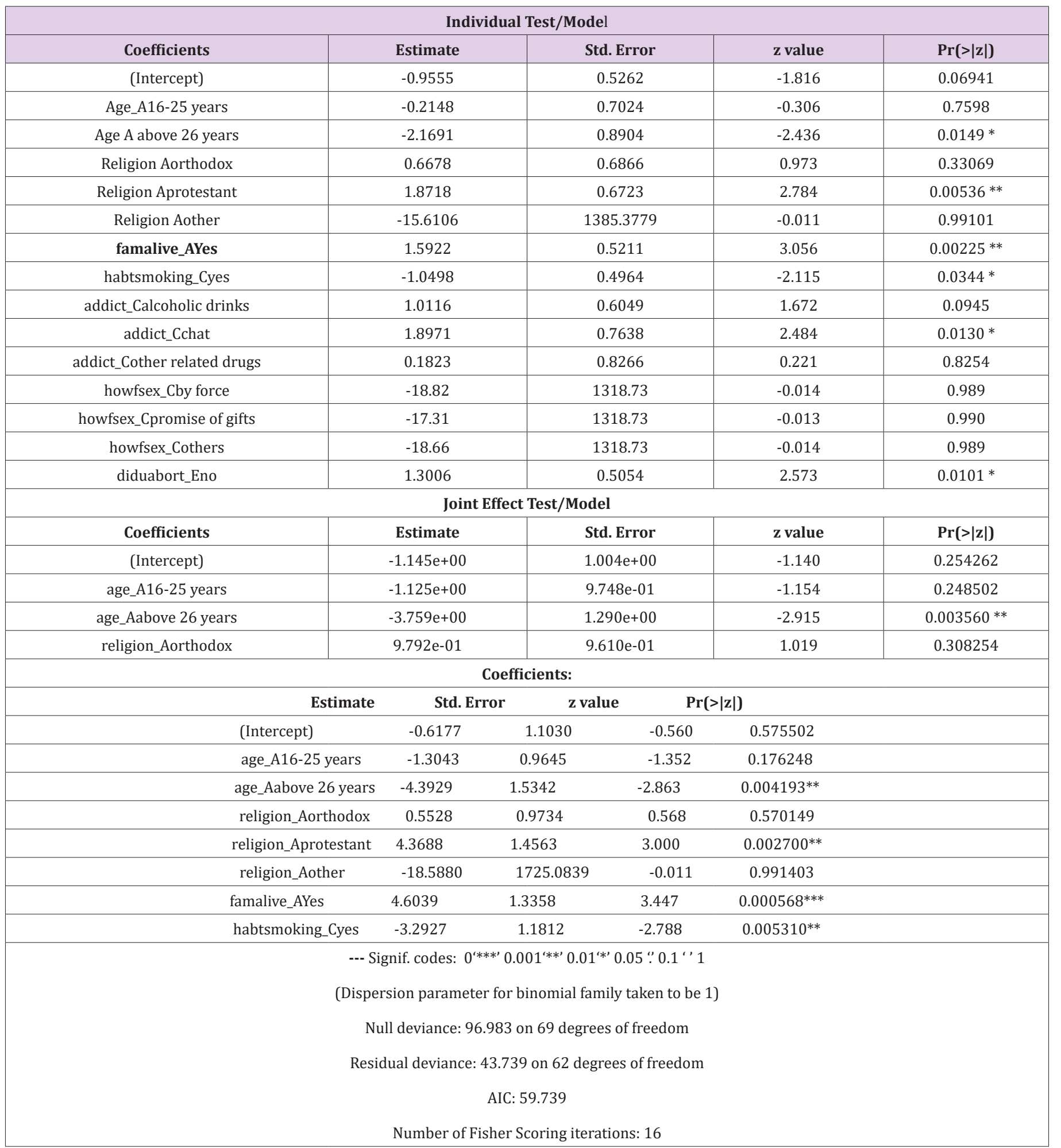


a) Individual Test Model: Age is significantly related to prostitution practice of females. After controlling all other variables in the model, the odds ratio of prostitution practice of females above 26 years is $\exp (-2.1691)=0.1142804(97.5 \%$ CI: $0.0007455005,0.4409633)$ times lower compared to those age less than or equal to 15 years (this means the probability of prostitution practice reduced by $11.4 \%$ for females above 26 years as compared to the counterpart), keeping the other variables constant in the model. The odds of being of prostitute for Orthodox religion females is $\exp (0.6678)=1.949943$ (97.5\% CI: 0.005617391, 2.328485) times higher when compared with the protestants.

The odds of being of prostitute for females whose families are alive during their entry is $\exp (1.5922)=4.914549(97.5 \% \mathrm{CI}$ : $1.8216039,14.226343$ ) times higher when compared with the protestants. The odds of being of prostitute for females who are smokers is $\exp (-1.0498)=0.3500077$ (97.5\% CI: 0.1289597 0.9118491 ) times lower when compared with those who are non-smokers. The odds of being of prostitute for females who chews chat is $\exp 1.8971)=6.666533(97.5 \%$ CI: 1.6299165 , 35.073139) times higher when compared with those who are alcohol drinkers. The odds ratio of prostitution for females who abort is $\exp (1.3006)=3.6(1.3918332,10.2020502)$.

b) Joint Effect Test/Model: In the joint effect model we see the same approach observed in the individual test model though some variables are insignificant in the joint model significant in the individual model. And the same parameter estimate interpretation work for this model. However, the joint model is the best model as it has smaller value of AIC which is 59.739 as compared to individual models.

\section{Discussion}

Prostitution is the act of providing sexual services to another person in turn for payment people who execute such activity. The objective of this study was to identify factors that induce females to engage into prostitution at Hossana town, South Ethiopia. To meet the objective, seventy female prostitutes were participated in the study which number is small as compared to other cases. This is because the act is too secret and unaccepted among the society and which made them hide themselves and even due to their unwillingness they were paid fifty birr per each questionnaire for each of them. Among these, most of them are from rural areas. Adolescent age females are very common to be exposed to the act as compared to young females below age 15 years as revealed by the study conducted in Jimma Zone. As revealed by the study done by Mekonnen and Asresash [13], the proportion of prostitution practice is large for smokers as compared to non-smokers.

According to the report of HAPCO, WHO $[14,15]$, the most important bad consequence of sex worker is high risk of acquiring, as occupational hazard, and increasing the spread of sexually transmitted infection including HIV/AIDS. Furthermore, another
Surveillance study conducted in Ethiopia in all regions between July 2013 and January 2014 show, HIV prevalence among female sex workers was estimated as $23.8 \%$ [16]. Studies conducted by Bright (2005) show the same result as areas of street prostitution showed that they are highly vulnerable to problems and challenges.

\section{Conclusion and Recommendation}

\section{Conclusion}

Most of the prostitutes are not interested in their acts. They are not happy with the act and even they did not engage into the act by their interest which implies there is the pushing factor behind. In average, adolescent age females are very common to be exposed to the act as compared to young females below age 15 years. There is also a remarkable variation of prostitution practices due to place of residence of females/prostitutes. The proportion of being a prostitute for rural females is larger than females living in urban area. The proportion of being prostitute for single female is larger than the married one. Females from the religion of protestant are more likely to be prostitutes as compared to Muslim. Most of the females stared the act when their families are alive. The proportion of prostitution practice is large for smokers as compared to nonsmokers.

The prevalence of prostitution is large for the way they get their clients on the street (road sites, main streets, in front of bars) as compared to they get their clients by living at hotel and get at night time. Most of the females engaged into the prostitution life to support their sick/poor family. Prostitutes frequently face difficulties like disagreement of number of turns, unwillingness of the clients to pay, pain, pregnancy, HIV, abortion, lacking interest, etc. The consequence of prostitution is revealed to bear child. Most of females engaged into the act born child. As the consequence of prostitution abortion is common among most of the females engaged into the act. Prostitutes are also exposed to sexually transmitted diseases. More than half of the responds in the study who are positive of STDs need support. As the result reveals, the determining factors for females engaged into prostitution are age level (adolescent), religion type (protestant), family life status(alive), habit of smoking(smokers), addiction (chewing khat), child bearing.

\section{Recommendation}

It is revealed that there are determining factors push females to be prostitutes. Hence, these factors should be controlled, though it is impossible to demolish the act absolutely. Thus,

\section{a) Prostitution should not be Tolerated:}

a) prostitution is heavily discouraged and seen as a social problem (should be abolished)

b) It is a form of violence against women, it is a violation of human rights, and the clients of the prostitutes exploit the prostitutes. Prostitutes are not prosecuted, but their clients and pimps are, (apply Neo-abolitionism). 
c) Both prostitutes and clients should be criminalized and should be seen as immoral, they should be considered criminals (apply Prohibitionism).

d) Attitudes of females should be changed, refreshed and they should be clean minded.

e) Continuous aware creation among prostitutes or every female should be revealed may be by any communication media.

f) There should be a policy directing how females will be winners of addiction of the act.

g) They should be cooperated in to five or as they like to be engaged in to the small and micro-enterprises to generate income instead of seeking it by selling their body, which should be supported by government, non-governmental institutions or and by any of the society members.

\section{Compliance with Ethical Standards}

a) Ethical Approval: All procedures performed in the study involving human (female) participants were in accordance with the ethical standards of the institutional and/or national research committee and with the 1964 Helsinki declaration and its later amendments or comparable ethical standards.

b) Informed Consent: Informed consent was obtained from all individual participants included in the study.

c) Fund Status: This study was not funded by anyone. Null fund at all, done by self strive.

d) Authors' Conflict of Interest: No conflict of interest among the authors.

e) Publication Fee Charging Capacity: No bursary, looking for compassionate body.

\section{References}

1. (2013) Prostitution-Definition and More from the Free MerriamWebster Dictionary. Merriam-Webster.
2. (2013) Prostitution Law \& Legal Definition. US Legal.

3. Parker Joe (1998) How Prostitution Works. Prostitution Research \& Education. Retrieved on 2009-09-03.

4. Julie Bindel (2018) Prostitution is not a job. The inside of a woman's body is not a workplace.

5. Jewkes R (2002) Overview of sexual violence against women in South Africa: Paper presented at consultation on sexual violence against women.

6. (2004) World Health Organization (WHO) Issues in Adolescent Health and Development, Geneva.

7. David A Freedman (2009) Statistical Models: Theory and Practice. Cambridge University Press p. 128.

8. Park, Hun Myoung (2009) Regression Models for Binary Dependent Variables Using Stata, SAS, R, LIMDEP, and SPSS. Working Paper. The University Information Technology Services (UITS) Center for Statistical and Mathematical Computing, Indiana University".

9. Hosmer D, S Lemeshow, Susanne May (1998) Applied survival analysis: Regression Modeling of Time to Event Data. Wiley New York, USA.

10. Collett D (1994) Modeling survival data in medical research. London Chapman \& Hall.

11. Mekonnen Gorfu, Asresash Demisse (2007) Sexual Violence against Schoolgirls in Jimma Zone: Prevalence, patterns, and consequences. Ethiop J Educ and Sc 2(2).

12. HAPCO (2014) Country Progress Report on the HIV Response, 2014.

13. WHO (2012) Global Health Observatory (GHO) data.

14.EPHI and CDC (2014) Report on the Sentinel Surveillance of Sexually Transmitted Infections.

15. Bright, Robert GL Pryor (2003) The Chaos Theory of Careers - Research Gate.

16. Burnette ML, Lucas E, Ilgen M, Frayne SM, Mayo J, et al. (2008) Prevalence and Health Correlates of Prostitution Among Patients Entering Treatment for Substance Use Disorders. Arch Gen Psychiatry 65(3): 337-344

17. Cecilia Hofmann (1997) "SEX: From human intimacy to "sexual labor" or Is prostitution a human right?" CATW-Asia Pacific. Retrieved 201005-09.

18. Jeff Francoeurs (2002) Minor league teammates tricked him into thinking a pitcher was deaf. USA Today.

19. Whisnant Rebecca; Stark, Christine (2004) Not for sale: feminists resisting prostitution and pornography. North Melbourne, Victoria, Australia: Spinifex Press. ISBN 9781876756499.
ISSN: 2574-1241

DOI: 10.26717/BJSTR.2019.23.003930

Getachew Tekle. Biomed J Sci \& Tech Res

(C) This work is licensed under Creative

Submission Link: https://biomedres.us/submit-manuscript.php

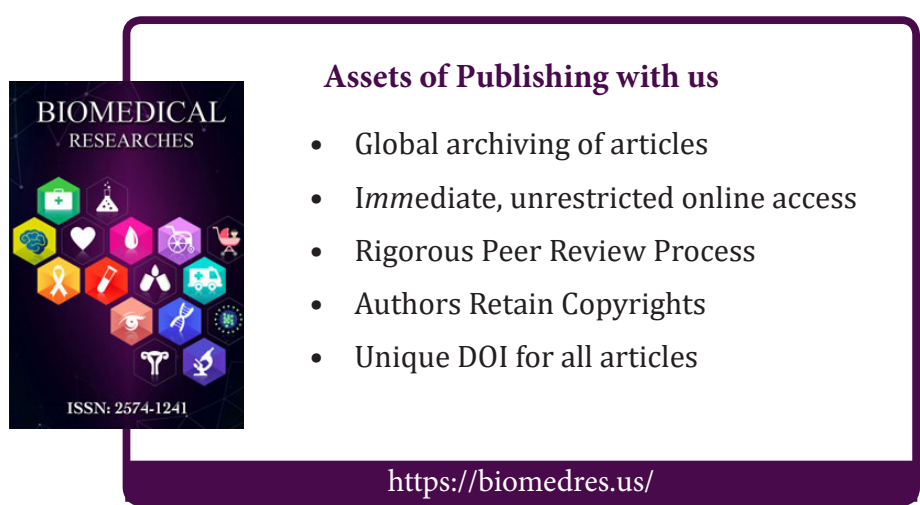

